\title{
Trainee Teachers' e-Skills, Participation and Views of e-blended Lessons: The Case of a Master of Arts Teacher Education Course
}

\author{
Tesfaye Habtemariam Gezahegn (PhD in TEFL) \\ Arba Minch University
}

\begin{abstract}
This case study aimed to explore English Language Trainee teachers' e-skills, participation and views to locally developed e-blended lessons of a postgraduate Teaching English as a Foreign Language (TEFL) course in an Ethiopian University. To do this, the teacher-researcher made a pre-course observation of the thirteen participants' e-skills, conducted two sessions of post-course focus group discussions with nine randomly selected participants and analyzed the digital log data of all the participants of the course. The data from participant observation and focus group discussions were analyzed qualitatively while the digital log data was analyzed using frequency count and mean. Hence, the study revealed that despite the variations in the sub-skills observed ten of the participants had the required e-skills at the start and most of them favored the approach of learning. However, some of them were also discontented by their limed access to computers and internet connection when they were off-campus. The result also showed that the students viewed and posted on all the 19 online activities of the course an average of 59.58. This shows their level of participation in the e-blended activities. Therefore, teacher trainers should consider using e-blended learning in their teacher education courses.
\end{abstract}

Key terms: e-blended, participation, trainee-teachers, views

DOI: $10.7176 / \mathrm{JEP} / 12-07-04$

Publication date:March $31^{\text {st }} 2021$

\section{Introduction}

Computer technology has significantly affected the way people communicate and do things. People are no more doing things in a way they used to do before the introduction of this technology. English language being the major medium, their social interaction has extended beyond boarders with the help of this technology. Facebook is a living proof in this regard. The learning and teaching as an aspect of their today's life is exceedingly affected by computer technology. Fox $(2011$, p.2) writes, "Today more than at any other time, the potential for technology to provide a major catalyst for change in what we do and how we do it in education has never been more apparent." This is true to the teaching and learning in higher education in Ethiopia. It is now difficult to say no to computer technology in our classrooms as students continue accessing it beyond our control. Relating this to language Hockly (2012, p.110) states, "It is increasingly difficult for us to separate language from the digital environment in which it is being used." As Chapelle (2006, p. ix) states, "The growth of the Internet and proliferation of computers in school and home settings has led to a significant expansion of the use of technology in foreign and second language instruction." This application of computer into Second or Foreign Language Learning situation is almost always referred as "Computer Assisted Language Learning (CALL)."

CALL, being "concerned with teaching and learning of second-languages through computer technology" (Chapelle, 2006, p. VII), has become an important tool in enhancing language learning nowadays. Kessler (2006, p.23) writes, "The use of CALL in language programs has become a standard and expected part of a curriculum." Among many of its forms as Neumeier (2005) states the blending of web-based CALL applications with face-to-face teaching and learning is becoming common around the globe. In the literature, terms such as 'blended' and 'hybrid' are most commonly associated to combined learning with internet and face-to-face contact. To Bliuc, et al (2007, p.234), "Blended learning' describes learning activities that involve a systematic combination of co-present [face-to-face] interactions and technologically-mediated interactions between students, teachers and learning resources." These two definitions clutch the main ideas in this study.

The growing acceptance of e-blended learning has probably come because of the theory of learning that informs it. Scholars assert that the theoretical framework of e-blended learning is the constructivist learning. Kim (2008) states that the assumptions underlying the benefits of computers in ESL/EFL context is their use in a student-centered and a constructivist learning approach, departing from a teacher-centered teaching approach. Pardo-Gonzalez (2013, p.57) also stated that the incorporation of learning resources in the web page changed the instructors' role and shifted to a learner-controlled environment. Vovides, et al. (2007) write that a e-blended approach allows instructors to offer students a more intellectually engaging learning experience by combining in-class time with online components. Thorne (2003, p.18) writes, "Blended learning represents a real opportunity to create learning experiences that can provide the right learning at the right time and in the right place for each and every individual at work, in schools, universities and even at home." Martín-Blas and Serrano-Fernández (2009) also indicated that one of the advantages of e-blended learning to students is the provision of unlimited access to the e-resources and e-learning sites in terms of time and space. Therefore, the 
underpinning theory in allowing students to control part of their learning through online components is because it is believed this provides a better learning experience than the Face-to-Face learning only. To further increase the effectiveness of this mode, teachers may need to supervise and encourage students during the online learning as they do for the face-to-face. They may need to schedule online forums and chat sessions with the students to allow learners reflect on the online learning aspect of the e-blended lessons.

Yet, this can only be possible if there is enough and reliable internet access. Currently, students and teachers are getting increased access to internet at their classrooms, libraries, cafés, dormitories, corridors, etc. in Ethiopia. In addition, the Ethiopian Education and Research Network (EthERNet) is consistently working for reliable internet in the higher education institutes, university students and teachers are possessing progressing ICT skills, digitized classrooms are emerging, Mobile Devices (e.g. cell phones, tablets, etc.) are becoming more abundant than ever. Moreover, more and more enthusiastic individuals are becoming interested in using ICT in education (e-learning) in Ethiopia. According to an e-learning survey by Unwin (2008) there is much enthusiasm amongst respondents from 42 African countries ( $9 \%$ of these are Ethiopian) for developing the potential of elearning in their countries.

On the other hand, even if TEFL teachers in Ethiopian Higher Education Institutions may not question the importance of e-blending in language teacher education, the researcher observes that its deliberate use is negligible and we seem to know little about how our learners' may react to its application in their courses. A survey by Hare (2007) indicates that the lecturers in Ethiopia are yet to adopt ICT as a teaching tool, and only a small number of students use computers and the internet as a learning resource. The studies by Elias (2014), Almaz (2013), Nebiyou (2012), Hirut (2011), Betremussie (2008), Molla (2008) and Lula (2007) also asserts this.

Arba Minch university which is the context of this study has already introduced e-blended learning mode. However, there are no studies conducted on the students' views and participation in these kinds of lessons. Hence, this study aimed to explore learners' pre-course e-skills, post-course views to an e-blended Masters Course named 'Lesson Planning and Classroom Management in ELT' and their frequency of participation (online viewing and posting). With these objectives in mind the following study design framework guided this study.

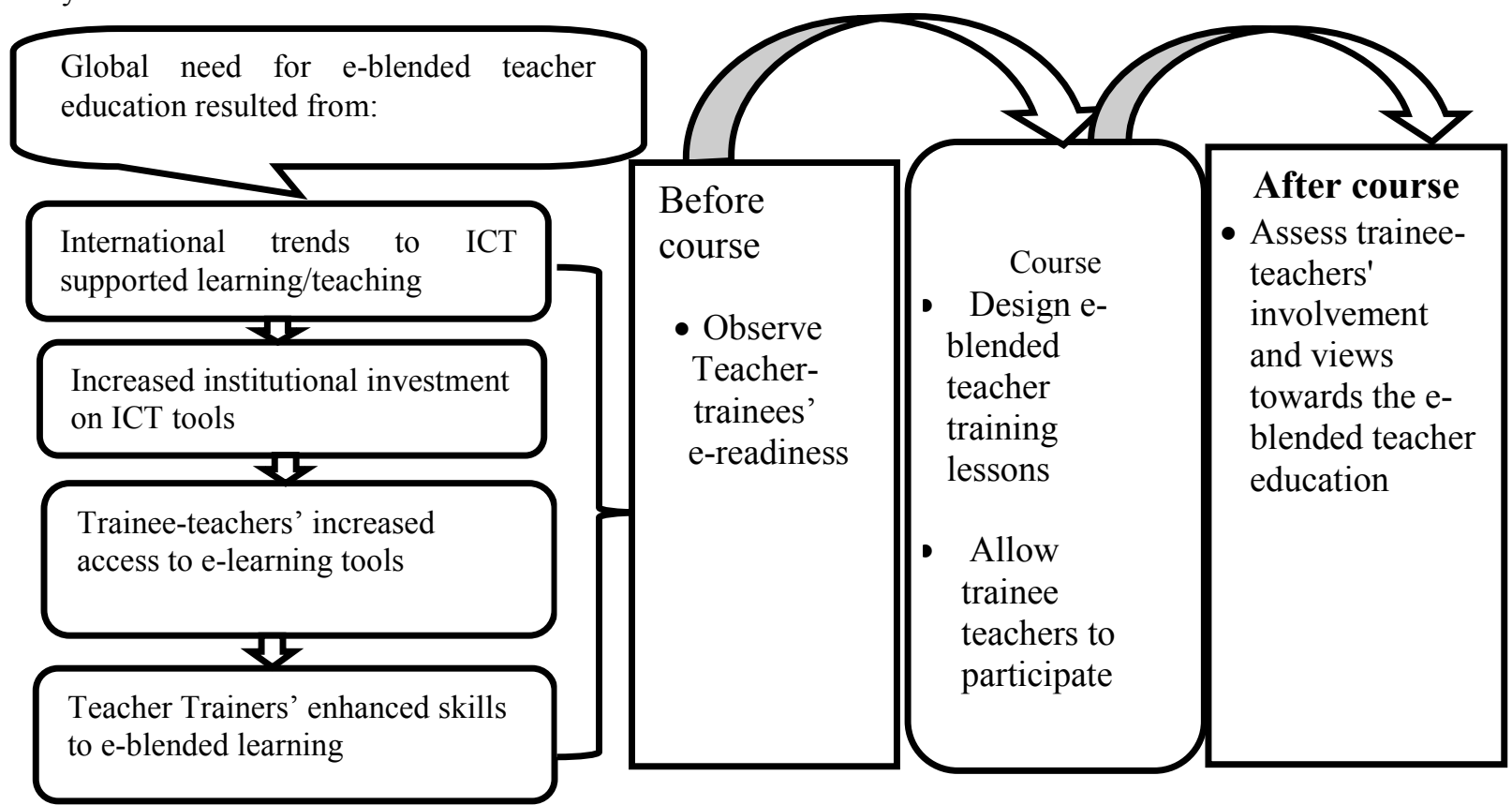

Figure 2: The design framework of the study

\section{Materials and Methods}

The study is a case study of one Teaching English as a Foreign Language (TEFL) MA class which was conducted in the second semester of 2013/14, largely relying on qualitative method based on data collected through a participant observation, focus group discussion and digital log data. The tools were used for three different purposes. A pre-course observation was made to know the initial e-skills of the participants, the two sessions of post course focus group discussions were conducted to explore participants' view and the post course digital log data was analysed to know participants' frequency of access to the online lessons.

As the researcher was the course instructor, the data collection and the teaching happened nearly concurrently. Consequently, the study passed through two procedural features. One was the course feature and 
the second was the data collection process. In fact, the course was not developed for the purpose of the study but it was used as the material for e-blending. Both features are described together below with a view of helping the reader.

\subsection{The Course features}

As a material for the study, the course design feature here refers to the approach opted to facilitate students learning that was described based on the "learning spaces, participants and materials" (Kupetz and Ziegenmeyer, 2005, p.179) with the addition of mode and duration of learning by the researcher.

- Learning spaces: the learning spaces were Moodle supported University e-learning platform for the online aspect and postgraduate classroom for the face-to-face contact of the course.

- Mode of learning: the modes of learning were scheduled face-to-face learning in the classroom and unscheduled online learning in the students' own time. This is what is termed e-blended learning in the context of this study.

- Participants: participants of the course were students as face-to-face and e-learners and the instructor as an ecourse organizer, face-to face learning facilitator and e-moderator.

- Materials: the online materials included the course syllabus, general over view of the course and course requirements, orientation to the online learning, e-books and e-articles related to the course, instructor's power point presentations (keynotes) on all the five units of the course, assignments for all the five units of the course and assessment criteria of each assignment and students' power point presentations. There were nineteen activities altogether. These can be accessed from http://elearning.amu.edu.et/ by providing appropriate user name and password.

- Duration of the course: The course took fourteen weeks of both face-to-face and online learning.

Below is a print screen of the online space for learning of the course indicated as accessed by the teacherresearcher on 12 April, 2014 from http://elearning.amu.edu.et.

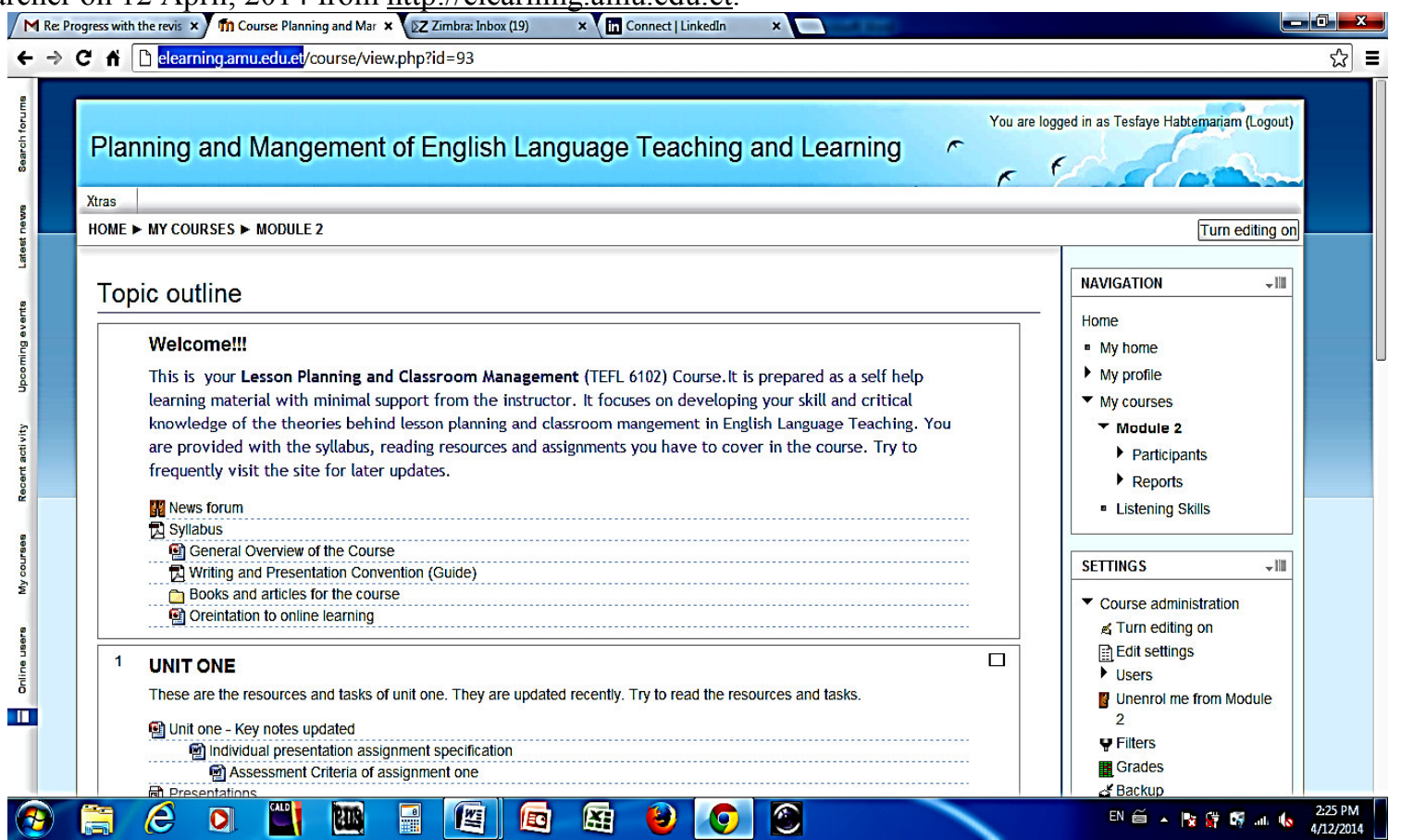

Figure 3: The online learning space for Lesson Planning and Classroom Management at AMU.

\subsection{Data collection procedures}

Data was collected in three ways: pre-course through participant observation, post course through observation of digital log data and focus group discussions.

Since the approach was the first of its kind for the target group, at the pre-course, data on learners' e-skills was collected with a purpose of examining learners' preparation for the e-blended approach in terms of the basic e-skills required for the course. Some of the basic e-skills listed in the observation checklist included: computer mouse and keyboard use, sending e-mail messages, downloading documents from e-mail messages, attaching documents to e-mail messages, writing on computer, opening files in a computer, on CDs or disks, organizing files and folders and creating new files and saving files in correct places on the computer. These according to Dvorak (2011) are the major skills required for the purpose of involving in computer assisted lessons. 
At the post course, two sessions of focus group discussions were made with a total of nine learners from the thirteen learners registered for the programme and an observation of participation report of online lessons was applied after two weeks of the class end which is after sixteen weeks of the pre-course. The focus group discussion included ten lead questions which focussed on exploring learners' views to the approach. These included whether they liked the online aspect of the course and which part, what they think was the most difficult aspect of the e-blended learning lessons, what aspect of the e-blended lessons they did not like and why not, how helpful they think was the e-blended learning to their learning of the course, how they think learning differed from their usual face-to-face learning, whether they wanted to take others courses of the programme in the same manner and their overall impression of the e-blended learning they attended. The participants were asked to note their answers to the ten lead questions before the actual focus group discussion was held. These notes were considered during the analysis of the data together with the participant observer's notes of the discussions.

\subsection{Methods of Data analysis}

The data analysis for the observation data was described in words. The twelve activities in the observation checklist were used as themes for analysis. Similarly, the data from focus group discussions were also organized into sub-themes based on the lead questions for focus group discussion. The digital log data was used to count the frequency of views and posts to the online aspect and the analysis of this part was made through the frequency count and mean values which was calculated by dividing the frequency of participation (views and posts) to the number of users of an online activity. To further consolidate the participation in the online aspects of the e-blended lessons an aggregation was also made. This was made through calculating the mean of the posts and views made to each of the nineteen online activities. All the computations were made using the Microsoft Office Spreadsheet (excel).

\section{Results and Discussion}

\subsection{Participants' e-learning skills}

In order to see if learners have the basic e-learning skills required for involving in e-blended learning a one-time observation was made on the first day of the class as part of the orientation to the online learning. Winke and Goertler (2008) emphasize the need to investigate students' computer access and literacy to estimate their readiness for hybrid language instruction.

\subsubsection{Mouse and keyboard use}

The learners were instructed to word process a text displayed on a projector. They were then observed how they used the mouse and keyboard. The measures for computer mouse and keyboard uses were leveled into three as fast and proficient, fast but do have to correct mistakes and as slow on the keys. With some room for subjectivity of the observation, eleven of the participants were observed to be fast but they have to occasionally correct mistakes during the using of the computer mouse while one of them was slow on the mouse. This was specifically observed as they put the courser in the wrong place and type words in this wrong place. On the other hand, one was exceptionally fast and proficient. Similarly, nine of them were fast but have to sometimes correct mistakes when using keyboard. This was seen as they pick on the letters from the keyboard to write words. The researcher generally observed that two of the participants were slow both on the keyboard and mouse use.

\subsubsection{Email message}

The items in the observation checklist included sending e-mail messages, downloading documents from e-mail messages and attaching documents to e-mail messages. The learners were asked to open an email message sent from the teacher researcher with some attachment. The contents of the email required the learners to reply back attaching any document of their own. Nine of them who had email addresses already could do what was asked while the rest four required teacher's support to open email addresses. Two of these four quickly learned how to send and open email message with the support of their classmates.

\subsubsection{Writing and organizing files}

The participants were asked to write something as a word document on a computer, save it on a flash disk with a folder name of their own choice. Eleven of them could perfectly do all the tasks while the rest two could only write something as word document.

As we can see from the result of the e-skills observation, majority of the participants (eleven out of the thirteen) had 'the necessary basic e-skills' indicated by Dvorak, (2011, p.3). Carrier (1997) asserts that some understanding of the technology is important for internet supported learning, that is, learners need basic digital skills to involve in e-blended learning in language education. The result has also showed that two of the participants did not have the required e-skills. These were hoped to develop the skills as they involve in the online learning. Hockly (2012, p. 110) claims, “... integrating new technologies into our classroom, we can also help learners develop key digital literacies [e-skills] and that it is indeed our duty as language teachers to do so." Marsh (2012, p.5) states one of the benefits of e-blended learning in CALL is that it helps students to develop 
valuable and necessary twenty-first century learning skills which according to McKenzie (2005) includes Information Technology Skills or e-learning skills. Meurant (2009) also confirms using LMS for EFL course websites is an effective means of developing student L2 Digital Literacy. This is probably the most important effect of involving in e-blended learning as it may shape their success and opinions to e-blended lessons.

\subsection{Participation in e-blended lessons}

To assess the students' participation in the online aspects of the course an observation of digital log data of student access of the e-learning site was made after two weeks of the class end. This is summarized in three sections namely the preliminary section, activities relating to instructors' notes and students' presentations and assessment related tasks of the course. Moodle (the learning management system used for the course) provides digital report of use on logs, activities and course participation. The course participation report was used for the purpose. This report shows frequency of online views and posts made by each participant. Rice IV (2006, p.197) asserts, "Moodle keeps detailed logs of all activities that users perform on your site. You can use these logs to determine who has been active in your site, what they did, and when they did it." Since the participants in the platform included teachers, course creator, students and guests, the online participation was filtered for including students only and all cases of views and posts.

\subsubsection{Participation in the preliminary section of the course}

The preliminary section of the online activities provided by the instructor included six sections. These are news forum for notices on the course; syllabus for the course contents, methods of teaching and assessment types; general overview to give the details of the course contents to be covered; writing and presentation convention to provide ideas on how to write assignments in the course; books and articles to provide the resources for reading and orientation to online learning for guiding the learners on how to access and explorer the activities in the course.

Table 1: Participants' Frequency of posts and views of the online resources in the preliminary section of the course

\begin{tabular}{|l|r|r|l|}
\hline Activities in the preliminary section & Frequency of views and posts & Users & Mean \\
\hline News forum & 65 & 11 & 5.91 \\
\hline Syllabus & 35 & 10 & 3.50 \\
\hline General Overview of the Course & 46 & 11 & 4.18 \\
\hline Writing and Presentation Convention (Guide) & 65 & 10 & 6.50 \\
\hline Books and articles for the course & 302 & 13 & 23.23 \\
\hline Orientation to online learning & 27 & 8 & 3.38 \\
\hline
\end{tabular}

Table 1 shows the books and the articles were the most frequently viewed section by fifteen users with a mean value of 23.23. This probably was because the books and the articles were required for the different assignments for the course and they had to visit them again and again. However, the orientation to online learning was the least viewed with a mean value of 3.4. The reason for limited views of this section seems to be that they were not required to frequently visit and post as they were provided the orientation by instructor during the first-class time.

\subsubsection{Participation in activities on instructor's and participants' presentation notes}

Participants' views and posts to the online aspects relating to instructor's and participants' presentation notes were analysed to evidence the extent of participation of the students in the online activities of these tasks. These are presented in the table below.

Table 2: Participants' Frequency of post and views of instructor's and participants' presentation notes

\begin{tabular}{|l|l|l|l|}
\hline Activities on instructor's and participants' presentation notes & $\begin{array}{l}\text { Frequency of } \\
\text { views and posts }\end{array}$ & users & Mean \\
\hline Unit one - Keynotes from the instructor & 120 & 10 & 12.00 \\
\hline Participants' Presentations on topics in unit one & 31 & 8 & 3.88 \\
\hline Unit two: keynotes from the instructor & 64 & 10 & 6.40 \\
\hline Presentations from participants on topics in unit two & 37 & 8 & 4.63 \\
\hline Key notes from the instructor on unit three & 59 & 8 & 7.38 \\
\hline Keynotes from the instructor on unit four & 37 & 8 & 4.63 \\
\hline Key notes from the instructor on unit five & 36 & 9 & 4.00 \\
\hline
\end{tabular}

According to table 2 the most frequently viewed and posted on was 'Unit one - Key notes from the instructor (Lesson planning in ELT') with an average view of 12 while the least viewed was the participants' presentations on topics in unit one with 3.88 mean value. The possible reason for frequent views of unit one is that the learners might have felt this part of the online source important. On the contrary, they might have felt viewing the presentation notes of their classmates less important as they have already attended the oral presentations. 


\subsubsection{Participation in assessment related activities}

Participants' views and posts to the online aspects relating to assessment in the course are presented in the table below.

Table 3: Participants' Frequency of post and views of assessment related activities

\begin{tabular}{|l|l|l|l|}
\hline Assessment related activities & Frequency of views and posts & users & Mean \\
\hline Assignment specification of unit one & 56 & 11 & 5.09 \\
\hline Assessment Criteria of assignment one & 15 & 4 & 3.75 \\
\hline Assignment two & 28 & 10 & 2.80 \\
\hline Assessment Criteria of assignment two & 17 & 6 & 2.83 \\
\hline Final Exam Topics & 54 & 9 & 6.00 \\
\hline The article for assignment two & 38 & 10 & 3.80 \\
\hline
\end{tabular}

Table 3 presents the Participants' Frequency of posts and views of assessment related activities. According to this table the most frequently viewed and posted on was Final exam topics with an average view of 6 per person while the least viewed was the assignment two with 2.80 mean value. The possible reason for frequent views of the final examination topics was that the assessment takes a large sum (40\%) of the total assessment.

Most of the participants viewed and posted on all the online activities for the course even if the average frequency of views and posts per person vary from one activity to the other.

\subsubsection{The aggregate value of participation on the e-blended activities}

To further consolidate the participation in the online aspects of the e-blended lessons an aggregation was made on the bases of the analysis made above. This was made through calculating the mean of the posts and views made to each of the nineteen online activities. The following table shows the total frequency of posts and views and the mean values of each of the three sections used for the analysis above together with the total aggregate values.

Table 4: The aggregate value of the participation in the e-blended lessons

\begin{tabular}{|l|l|l|c|}
\hline Types of online activities & $\begin{array}{l}\text { Number of online } \\
\text { activities }\end{array}$ & $\begin{array}{l}\text { Total Frequency of views and } \\
\text { posts }\end{array}$ & Mean \\
\hline Preliminary section of the course & 6 & 540 & 90.00 \\
\hline $\begin{array}{l}\text { Instructor's and students' presentation } \\
\text { notes }\end{array}$ & 7 & 384 & 54.86 \\
\hline Assessment related activities & 6 & 208 & 34.67 \\
\hline Total & 19 & 1132 & 59.58 \\
\hline
\end{tabular}

Table 4 shows the total frequency of views and post and number of activities with the mean values. As indicated, the average number of views and posts made to all the nineteen activities is nearly 60 . This shows that if Ethiopian trainee teachers were given the opportunity to involve in e-blended learning, they would frequently view and post on the activities provided online. The reason for this probably is the time, pace and space freedom the e-blended learning provides. Thorne $(2003$, p.18) writes, "Blended learning represents a real opportunity to create learning experiences that can provide the right learning at the right time and in the right place for each and every individual at work, in schools, universities and even at home."

\subsection{Participants' views towards e-blended learning}

Participants' view of the e-blended learning was explored through the focus group discussions. The discussions happened after two weeks of the end of the course and once it was graded to minimize forged responses that might have been given to please the teacher-researcher. The researcher was leading the discussion by taking the group from one question to the other but he remained at the background during the discussion. The analysis of the focus group discussion was made in sub-themes as follows.

\subsubsection{Participants' view to the aspects they favoured about the approach}

As stated earlier, after their involvement in the e-blended lessons provided by their instructor, the groups were asked whether they liked the online aspect of the course and which particular part they particularly liked.

Except two, all the other seven stated that they liked the online aspect of the course for it provided them with the resources required for the course and because it helped them enjoy the freedom of accessing the online resources anyplace and anytime. One of them in particular mentioned that

As I get the library on a single window of my computer, I liked the online learning. It saved my time. If I were to look for the resources and the ideas on the teacher's key notes from the library it would require me a lot of time, I may even not get the materials in the library. To be honest, I really enjoyed accessing the e-resources. It reduced my tension reducing the pressure of time shortage. As I stay on campus, I always explore them in the postgraduate computer laboratory because it was a new world to me (code 05).

The reasons for their favouring of the e-blended lessons seems to focus on the freedom of time and place of 
access they provide them to the resources and it was because the lessons also reduced their tension.

\subsubsection{Participants' view to the aspects of the approach they disapproved}

The group were also asked what they think was the most difficult aspect of the e-blended lessons, what aspect of the e-blended lessons they did not like and why not. Their responses to the most difficult aspect of the e-blended lessons were varied. Three of them stated that they did not have enough access to computers when they were offcampus. They thought this restricted their access to e-blended lessons. Two others commented that the internet connection itself was an issue. They stated that internet connection was sometimes down when they have just badly needed to access the course. One specifically mentioned that navigating through the e-learning site sometimes became difficult for the reason he could not figure out. He stated them in his actual words as follows. As I always did I used my password and username you (the teacher) gave us but opening the e-books was really impossible. I really needed to open them because I had to read them for the assignment you gave us. In the meantime, power went and I waited for half an hour to reconnect. I was lucky this time; I could easily reconnect using the same process but I wonder why I could not open it in my earlier attempt (code 11).

Regarding the aspects they did not like about the online aspect of the e-blended learning three of them did not say anything though they were probed in indifferent ways while six of them stated that there was no aspect they did not like. This shows that if the the issues the participants mentioned are not reduced e-blended lessons may not be fully favoured by the learners.

\subsubsection{Participants' view to how helpful the approach is and their interest take courses in the same manner}

Our discussion further included lead questions such as how helpful they think the e-blended learning to their learning of the course was, how they think e-blended learning differed from their usual face-to-face learning, whether they wanted to take others courses of the programme in the same manner. Even if they phrased them slightly differently five of them assured that the online aspects helped them strengthen what they have learned in their face-to-face lessons. To mention what code 13 said:

It was very important because the lesson I attended from the teacher (face-to-face) was strengthened by accessing online contents. Whenever, I'm in doubt I know where to look for, the online resources are the answers. The only thing I needed to do is use my username and password the teacher gave me.

Concerning, how they think e-blended learning differed from their usual face-to-face learning all but two said because it helped them learning through an additional dimension while still, they had the chance to learn on the usual face-to-face learning. They further stated that the online aspect of the e-blended learning encouraged them to explore further on using the computer for their own future teaching. Regarding whether they wanted to take other courses of the programme in the same manner all said 'yes' but three further explained that they need to feel confident about their e-skills before involving.

\subsubsection{Participants' overall impression to the approach}

Their overall impression of the e-blended learning they attended was the other item of discussion. With some variations in their phrasing six of them were happy that they got the chance to attend their course this way. To quote some here,

I liked it very much because it introduced me with the new technology and it broadened my knowledge in different aspects, the way you (the teacher) organised it was really interesting. I think you need to share this to other teachers in the programme (code 09).

Another respondent on the same issue said:

E-learning is a whole new world for me and most of my classmates. It is important therefore to think of it as innovative way of learning with new and sometimes different learning skills. Success in blended elearning adds value to my professional development; it offered me a flexible and enjoyable learning experience (code 04).

A third respondent commented about the limitations of the approach though she admired it.

Admirable but computer access was really a problem. I wish I did not have to work and learn at the same time. I could have benefited more as I can always access the computers on campus (code 07).

Even though some of them mentioned limited access to computer as an issue, their overall impression to the approach was positive. This agrees with Ushida (2005) cited in Sagarra and Zapata (2008) who found that second language students' perception in language course with a strong online component resulted in positive attitudes toward the use of the technology for learning. Motschnig-Pitrik and Mallich, (2004) in their study of the effects of Person-Centred attitudes on professional and social competence in an e-blended learning paradigm have also observed that their approach has been perceived as a highly constructive mode of sharing and learning cooperatively. Furthermore, explaining their view to the approach all the participants of the discussion agreed that they want to take other courses of the programme in the same manner. Fisher (2009) found that the participants in her study witnessing good classroom practice where the technology was benefiting learning, they positively viewed its use for their own future work. 


\section{Conclusions}

The findings in this study showed that the majority of the trainee teachers had the e-skills required for e-blended learning before the start of the course, most of them had posted on and viewed the e-blended activities in the course and positively viewed their e-blended learning experience. If teacher moderation and encouragement was added, the learners might have participated more meaningfully than observed in this study. Therefore, teacher trainers should consider using e-blended learning in their teacher education courses. However, we still need to take a statistically sufficient sample to draw wide-ranging conclusions. Moreover, using frequency of views and posts in the digital log data to show participation in a course has the limitation of showing the duration and level of participation. Other researchers may need to look into these variables to qualify participation.

\section{References}

Almaz Abuhay (2013) Learning Through Information Technology: Challenges and Opportunities in Learning through Information Communication Technology in Addis Ababa University; the Case of Students with Visual Impairment. A Thesis Submitted to the School of Social Work, Addis Ababa University. Unpublished.

Arba Minch University (2014). Retrieved from http://elearning.amu.edu.et accessed April 12, 2014.

Betremussie Tadesse (2008). Design and Implementation of a Web based Distance Education in Ethiopia: MSc thesis: Addis Ababa University: Unpublished.

Bliuc, A., Goodyear, P. and Ellis, R. A. (2007). Research focus and methodological choices in studies into students' experiences of blended learning in higher education. Internet and Higher Education 10, PP.231244.

Carrier, M. (1997). ELT online: the rise of the Internet. ELT Journal Volume 51/3

Chapelle, C.A. (2006). Introduction. In Hubbard, P. and Levy, M. (eds.) Teacher Education in CALL. Amsterdam: John Benjamins

Dvorak, R. (2011). Moodle for Dummies. USA: Wiley Publishing.

Elias Lemma Beyene (2014). The Status of the Implementation of Information and Communications Technology in Distance Education. A Thesis Presented to Department of Curriculum and Teachers Professional Development Studies for the Degree of Master of Arts in Adult and Life Long Learning. Addis Ababa University. Unpublished.

Fisher, L. (2009). Trainee teachers' perception of the use of digital technology in the language classroom. In Evans, M. J. (ed.) Foreign-Language Learning with Digital Technology. USA: Continuum.

Fox, R. (2011). Technological Practice and Change in Education. In Kwan, R., McNaught C., Tsang, P., LeeWang. F., Li, K. C. (Eds.) Enhancing Learning Through Technology: Education Unplugged: Mobile Technologies and Web 2.0. London: Springer.

Hare, H. (2007). "Survey of ICT in Education in Ethiopia". Survey of ICT and Education in Africa (Volume 2): 53 Country Reports. Washington, DC: infoDev / World Bank. Retrieved from http://www.infodev.org accessed on March 6, 2013.

Hirut Berhe (2011). The Challenges and Current Status of elearning in Ethiopian Higher Education Institutions: Case of Mekelle University. Thesis Submitted to the School of Graduate Studies for the Degree of Master of Science in Information Science. Addis Ababa University. Unpublished.

Hockly, N. (2012). Technology for the language teacher: Digital literacies. ELT Journal 66 (1), PP.108-112.

Kessler, G. (2006). Assessing CALL teacher training: What are we doing and what could we do better? In Hubbard, P. and Levy, M. (eds.) Teacher Education in CALL. Amsterdam: John Benjamins.

Kim, H.K. (2008). Beyond Motivation: ESL/EFL Teachers' Perceptions of the Role of Computers. CALICO Journal, 25, (2), 241-259.

Kupetz, R. and Ziegenmeyer, B. (2005). Blended learning in a teacher training course: Integrated interactive elearning and contact learning. ReCALL / Volume 17 / 2, PP.179 -196.

Lula Tewfik (2007). An Exploratory Study of Internet Use for Education and Research by Postgraduates in AAU.A Thesis Submitted for the Degree of Master of Art in Journalism and Communication. Addis Ababa University. Unpublished.

Marsh, D. (2012). Blended Learning: Creating Learning Opportunities for Language Learners. Cambridge: Cambridge University Press.

Martín-Blas, T., and Serrano-Fernández, A. (2009). The role of new technologies in the learning process: Moodle as a teaching tool in Physics. Computers \& Education 52 PP.35-44.

McKenzie, W (2005). Multiple Intelligences and Instructional Technology. Second Edition.

Washington DC: International Society Technology for Education.

Meurant, R.C. (2009). The Use of Computer-based Internet-hosted Learning Management Systems, particularly Moodle, to Develop Critical L2 Digital Literacy. Presented to the Seoul International Conference on Linguistic Interfaces. 
Molla Mitiku (2008). Internet Application in Teaching/Learning English as a Foreign Language: With reference to Sophomore English. MA thesis Submitted to the Department of Foreign Languages and Literature at Addis Ababa University. Unpublished.

Motschnig-Pitrik, R., \& Mallich, K. (2004). Effects of Person-Centered Attitudes on Professional and Social Competence in a Blended Learning Paradigm. Educational Technology \& Society, 7 (4), pp.176-192.

Nebiyou Tekle, (2012). Assessment of the Application of Educational Technology: The Case of the use of elessons at Kotebe College of Teachers' Education. A Thesis Submitted to The Department of Educational Research and Development, Addis Ababa University. Unpublished.

Neumeier, P. (2005). A closer look at blended learning - parameters for designing a blended learning environment for language teaching and learning. ReCALL 17 (2), pp. 163-178.

Pardo-Gonzalez, J. (2013). Incorporating blended learning in an undergraduate English course in Colombia. In Tomlinson, B. and Whittaker, C. (Editors) Blended Learning in English Language Teaching: Course Design and Implementation. London: British Council.

Rice IV, W. H. (2006). Moodle E-Learning Course Development: A complete guide to successful learning using Moodle. UK: Packt publishing.

Sagarra, N. and Zapata, G. (2008). Blending classroom instruction with online homework: A study of student perception of computer-assisted L2 learning. ReCALL 20(2), pp. 208-224.

Thorne, K. (2003). Blend M. (ed.) Comparative Blended Learning Practices and Environments. USA: IGI Global.

Vovides, Y., Sanchez-Alonso, S., Mitropoulou, V. \& Nickmans, G. (2007). The use of e-learning course management systems to support learning strategies and to improve self-regulated learning. Educational Research Review 2, 64-74.

Winke, P. \& Goertler, S. (2008). Did We Forget Someone? Students' Computer Access and Literacy for CALL. CALICO Journal, 25 (3), pp. 482-509. 